\title{
[Rh-Pd] Ionic Gel-Soaked Bimetallic Catalyst
}
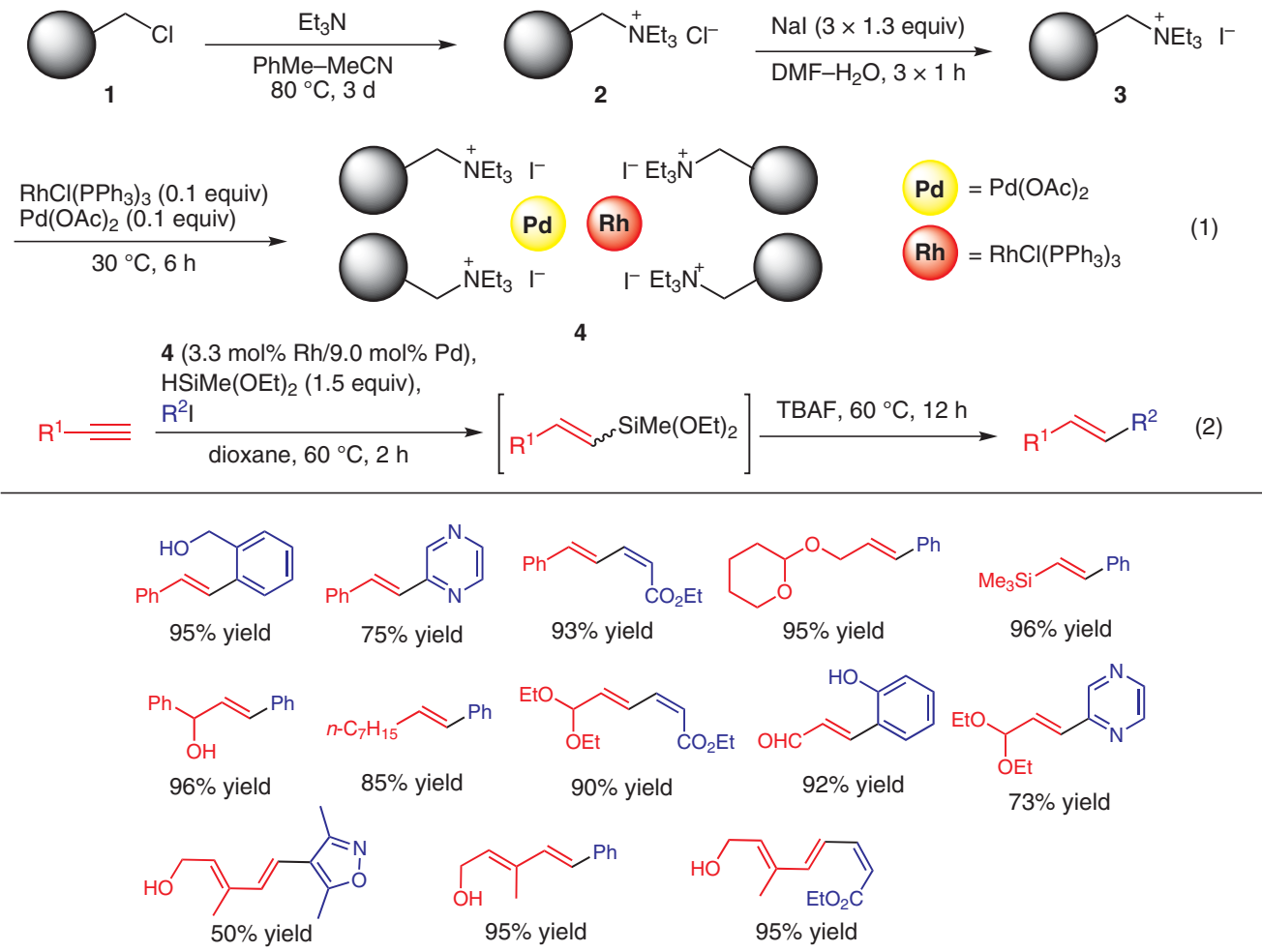

Significance: The [Rh-Pd] ionic gel-soaked bimetallic catalyst for the one-pot hydrosilylation/Hiyama cross-coupling reactions was described. Thus, the reaction of Merrifield resin $\mathbf{1}$ with $\mathrm{Et}_{3} \mathrm{~N}$, followed by the anion exchange of $\mathbf{2}$ with $\mathrm{Nal}$ afforded the polyionic iodide gel $\mathbf{3}$. The polyionic iodide gel $\mathbf{3}$ was treated with $\mathrm{RhCl}\left(\mathrm{PPh}_{3}\right)_{3}$ and $\mathrm{Pd}(\mathrm{OAc})_{2}$ to provide the [Rh-Pd] bimetallic catalyst 4. The one-pot synthesis of $E$-disubstituted alkene via hydrosilylation/Hiyama cross-coupling reaction was carried out in dioxane in the presence of $\mathbf{4}$ and subsequent addition of TBAF to give the corresponding $E$-alkenes in 50-95\% yield.
Comment: It is noteworthy that the Sonogashira coupling side products were not obtained, even without sequential addition of coupling partners in the present procedure. The high chemoselectivity is attributed to a slower Sonogashira coupling in polyionic gel in the absence of copper co-catalysts. For the reaction of phenyl acetylene with phenyl iodide, the catalyst can be recycled three times without loss of the catalytic activity and stereoselectivity (>99\% yield and $E / Z>99: 1$ for 1 st3rd cycles); however, the product yield decreased in the 4th cycle (78\% yield and $E / Z>99: 1)$. 